\title{
Betriebsausflug 2015 nach Straßburg
}

11. Februar 2015: Die Württembergische Landesbibliothek (WLB) lädt zu einem Festakt anlässlich des 250-jährigen Jubiläums in das Haus der Wirtschaft. Ausgewählte Redner waren geladen und sprachen ernste, aufmunternde und auch humorvolle Worte voller Freundschaft. So auch der Generaldirektor der Bibliothèque nationale et universitaire de Strasbourg (BNU), Herr Albert Poirot, der in seiner Rede auch die Partnerschaft der beiden Bibliotheken aufgreift und ihre Lebendigkeit betont.

Um diese lebendige Partnerschaft erneut zu bestätigen, entstand die Idee, im Rahmen des diesjährigen Betriebsausflugs die neue BNU zu besuchen.

Nach einigen zusätzlichen Absprachen ob der doch etwas größeren Entfernung zum Ziel des Betriebsausfluges ging es dann am 16. Juli 2015 um $8 \mathrm{Uhr}$ morgens mit zwei Bussen und über 80 Kolleginnen und Kollegen auf eine zweieinhalbstündige Fahrt nach Straßburg. Dank der erfahrenen Busfahrer konnten wir Staus umgehen und waren pünktlich da, um von Herrn Blin sehr herzlich begrüßt zu werden. Bereits nach ein paar Minuten wird er von einem stürmischen Applaus unterbrochen, als er erwähnt, dass die komplette Bibliothek "spécialement" für uns geschlossen wurde, um uns durch den Neubau führen zu können.

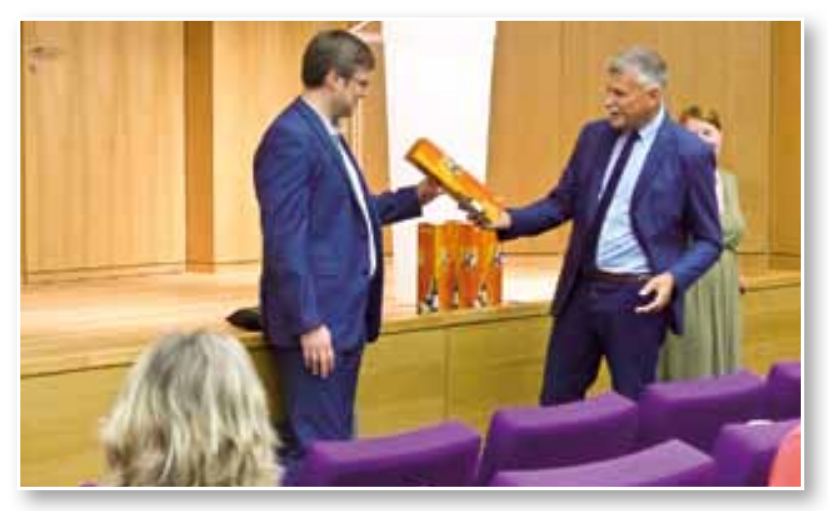

In insgesamt fünf Gruppen ging es auf unterschiedlichen Pfaden durch die Bibliothek, die nach Umbau und Modernisierung seit November letzten Jahres wieder geöffnet hat. Insgesamt 9 Jahre vergingen zwischen Finanzierungsbewilligung und vollständiger Neueröffnung (während der Bauarbeiten herrschte nur eingeschränkter Betrieb). 9 Jahre, die

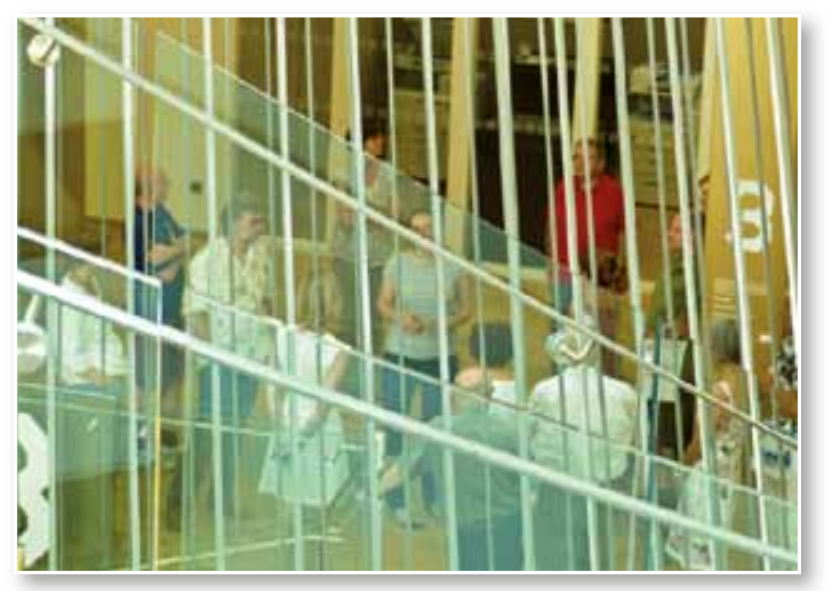

sich gelohnt haben, denn es ist ein großes und offenes Gebäude mit großzügigen Benutzungsflächen entstanden. Dabei wurde darauf geachtet, dass sich "Altes" und "Neues" harmonisch ergänzen, was sich in den hellen Farben mit kräftigen Akzenten in anthrazit, lila und gold erkennen ließ. Immer wieder sieht man Stellen, an denen noch alte Mauerreste zu finden sind. Bereits in der Vorhalle bekommt man ein Gefühl für das Konzept der neuen BNU: Die riesige Wendeltreppe, die nach oben schlanker wird, ist einfach und doch beeindruckend. Trotz der luftigen Höhen fällt der Aufstieg dank einer angenehmen Treppenhöhe nicht schwer. So kann man sich ganz

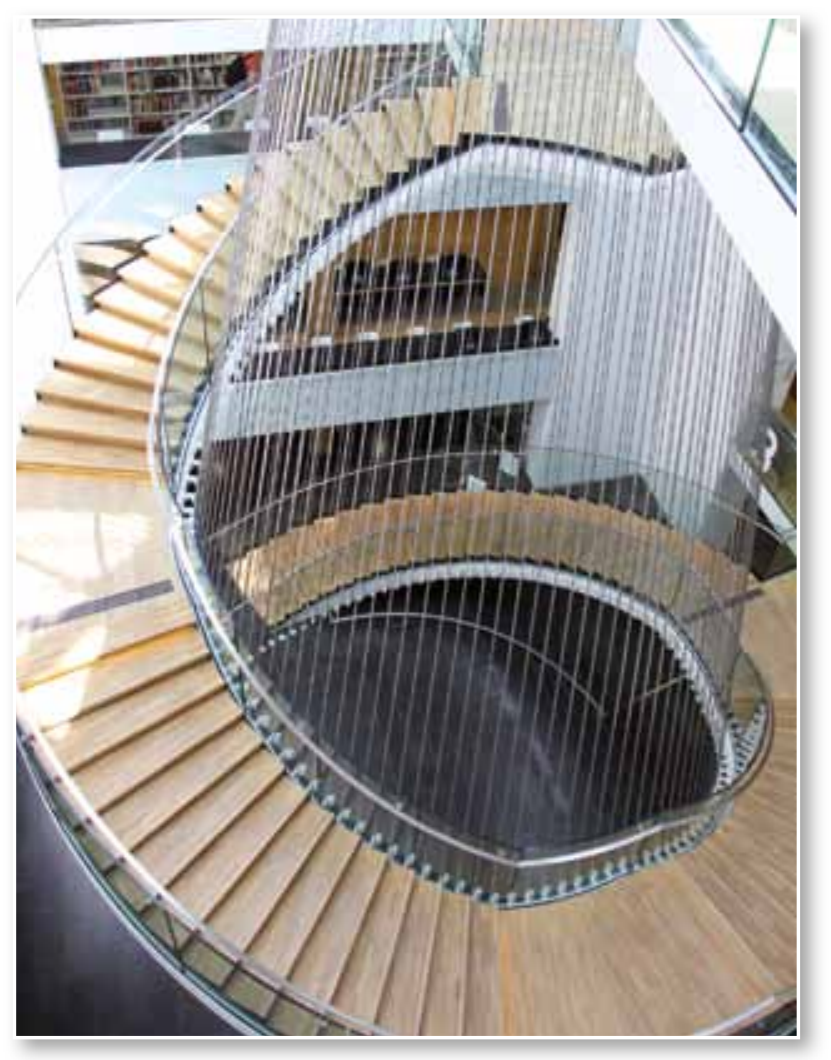



auf den Anblick der umliegenden Arbeitsplätze, Regale und Servicepunkte einlassen. Ein gutes Leitsystem erschließt das Gebäude. An prominenten Stellen wird durch Piktogramme beispielsweise darauf hingewiesen, dass überall Zugriff auf das WLAN oder die Mitnahme von Wasserflaschen möglich ist. Weiterhin konnten wir einen Blick in das historische Magazin werfen - Holzregale gefüllt mit alten Bänden - das als Reminiszenz an die Vergangenheit erhalten wurde. Wir konnten auch die verschiedenen Lesesäle, Ausstellungsräume, die Fernleihe, die Restaurierungswerkstatt und die Zeitschriftenstelle besichtigen. Nach einem kurzen Blick in die Mitarbeiterräume versammelten wir uns wieder im Vortragssaal der BNU, um uns, begeistert von der Bibliothek und den netten französischen Kolleginnen und Kollegen, zu verabschieden.

Ab circa 13 Uhr konnten wir den kurzen, zur freien Verfügung stehenden Nachmittag bei strahlendem Sonnenschein genießen. Einige nahmen an einer Bootstour teil, andere an einer 60-minütigen Führung durch das Münster (Cathédrale Notre-Dame de Strasbourg). Dieses zu den größten Sandsteinbauten gehörende Gotteshaus wurde zwischen 1176 und 1439 erbaut. Bis weit ins 19. Jahrhundert hinein war das Gebäude mit seinen 142 Metern das größte Bauwerk der Menschheit. Dank seines fehlenden Südturmes (der nie gebaut wurde) und seiner dadurch asymmetrischen Bauform ist das Straßburger Münster das Wahrzeichen des Elsass. Im Inneren des Gebäudes wurde vor allem auf die astronomische Uhr eingegangen. Seit 1574 existiert diese und lief bis 1789. Nach weiteren 50 Jahren wurde die Uhr renoviert und läuft bis heute. Ein außergewöhnliches Uhrwerk lässt jede Viertelstunde ein Glockenspiel erklingen, zur Mittagszeit kann man ein Schauspiel von Figuren betrachten, welches Apostel zeigt, die unter dem Flügelschlagen eines Hahns an Christus vorbeiziehen. Außerdem zeigt die Uhr die Umlaufbahn von Erde, Mond und der Planeten Merkur bis Saturn an. Nach der Tour im Inneren zeigte die Führerin den interessierten Kolleginnen und Kollegen noch Besonderheiten rund um das Münster.

Viele entschieden sich auch gegen ein festes Nachmittagsprogramm und schlenderten durch Straßburgs Straßen. Vor allem die Eisdielen erfreuten sich großer Beliebtheit, da die 36 Grad, wenn auch angenehmer als in Stuttgart, deutlich spürbar waren.

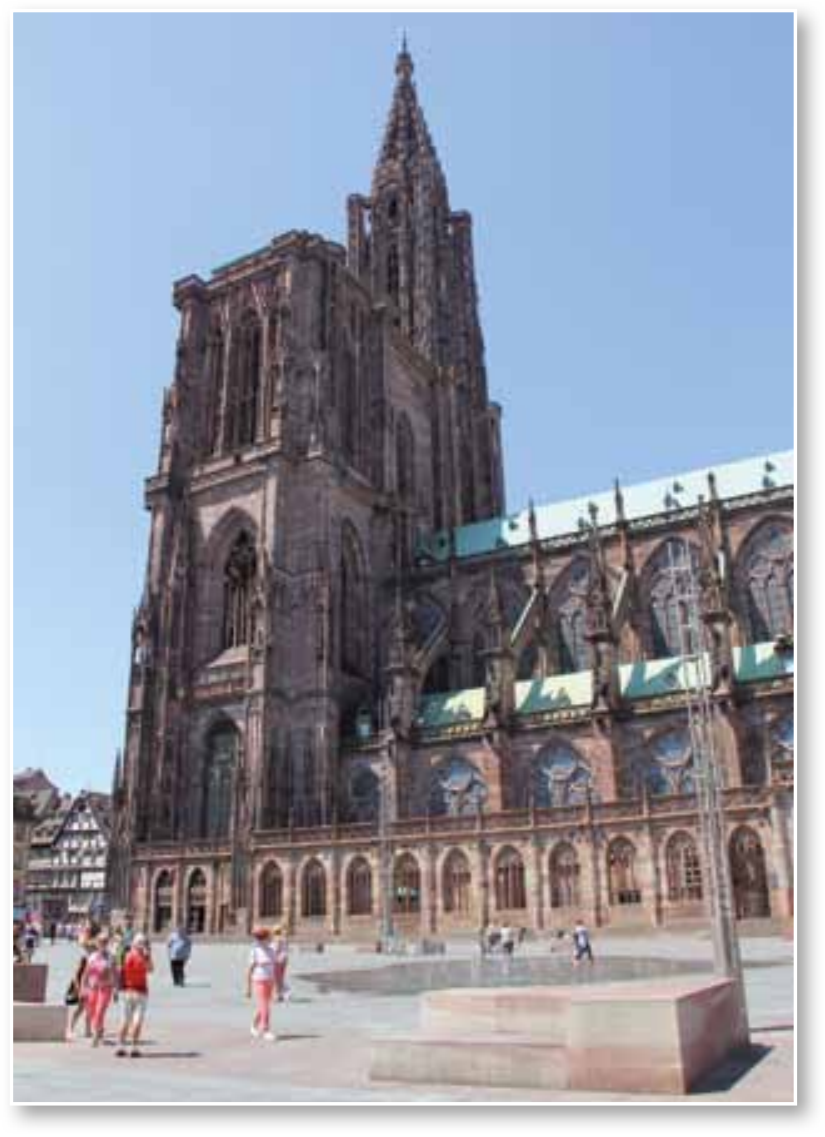

Der Teil Straßburgs um das Münster herum überzeugte durch einem gesunden Mix aus Patisserien, kleinen Läden und auch den unvermeidlichen Kettengeschäften, die sich aber geschickt ins Stadtbild eingefügen. Alles in allem hat der kurze Einblick in diese Stadt bei vielen Kolleginnen und Kollegen Lust auf einen erneuten Besuch geweckt.

Gegen 15:30 Uhr trafen wir uns wieder an den Bussen und fuhren zum Abschluss des Tages in ein Flammkuchenlokal nach Sessenheim. In gemütlicher Atmosphäre wurden schnell die ersten Getränke und Flammkuchen serviert. Über die traditionelle Variante mit Speck und Zwiebeln bis zu Flammkuchen mit Pilzen konnte man sich tischweise seine Favoriten aussuchen. Am Schluss wurde noch ein süßer Flammkuchen mit Äpfeln serviert, der auch den letzten noch satt und zufrieden gemacht haben dürfte.

Nach Ankunft gegen 20 Uhr war der bisher wohl längste Betriebsausflug vorbei, und es herrschte die einhellige Meinung, dass dieser rundum gelungen war. Jetzt geht es schon fast an die Planung des nächsten... 